\title{
Francisco Bautista, Carlos Laliena y Guillermo Tomás (COORds.), CUltura Y PODER DEL Estado en la Corona de ARaGón. Historiadores e HISTORIOGRAFÍA EN LOS SIGLOS XIII-XVI, ZARAGOZA, UniVERSIDAD DE ZARAGOZA, 2019, 272 PÁGS. ISBN: 978-84-1340-019-8.
}

\author{
Covadonga Valdaliso Casanova \\ Centro de História da Universidade de Lisboa \\ Universidad de Alcalá
}

Hasta fechas recientes el estudio de la historiografía escrita en la Corona de Aragón en la Edad Media ha estado condicionado por dos circunstancias: la riqueza documental de los archivos del territorio - que sustenta y sustentará investigaciones prácticamente imposibles de llevar adelante en muchos otros-y la idea de que las llamadas "cuatro grandes crónicas" son los textos más representativos de la producción historiográfica medieval aragonesa y, en buena medida, un buque insignia rodeado por una flota menor. A estos condicionantes se unen otros no exclusivos de esta Corona pero que parecen haberle afectado con bastante intensidad. El primero sería la agrupación de los textos en función de la lengua en la que estaban escritos, lo que en algunas ocasiones ha impedido reconocer vínculos entre ellos y en otras ha generado interpretaciones que llevan a preguntarse si la opción que el autor tomó en su día fue tan consciente y significativa como se pretende. El segundo, la proyección en el pasado de mapas contemporáneos que, incluso en los casos en que coinciden o se aproximan a las divisiones territoriales del periodo, evidentemente no representan las mismas realidades políticas ni institucionales. El tercero, la consideración de que la historiografía medieval se extinguió en el siglo $\mathrm{XVI}$, a pesar de que gran parte de los textos que conocemos se siguieron copiando y editando, y de que hubo una continuidad en la evolución de las formas historiográficas en época moderna.

El presente volumen aborda de manera directa la mayor parte de estas cuestiones tanto en su introducción, firmada por Carlos Laliena y Guillermo Tomás, como en sus conclusiones, redactadas por Francisco Bautista. Lo hacen también, si bien desde variadas perspectivas, las once contribuciones que lo componen, en las que Stefano M. Cingolani analiza la visión del pasado de Pedro el Ceremonioso, Francisco José Martínez Roy repasa la intensa relación con la historiografía de Juan Fernández de Heredia y su correspondencia sobre la temática con los monarcas coetáneos, Mateu Rodrigo Lizondo 
ofrece un amplio listado de los escritos historiográficos breves compuestos en buena parte de los territorios de la Corona en los siglos XIV y XV, Ángela Testa explora en paralelo dos espejos de príncipes humanistas compuestos en contextos muy diferentes, Fulvio Delle Donne estudia los ecos historiográficos de la huella ideológica imperial recibida por Alfonso el Magnánimo tras la conquista de Nápoles, Miguel Ángel Pallarés Jiménez comienza narrando la trayectoria reciente de un incunable de la Crónica de Aragón de Gauberto Fabricio de Vagad para luego pasar a hablar extensamente de la obra, su autor y sus fuentes, Teresa Jiménez Calvente presenta en paralelo el recorrido vital de Lucio Marineo Sículo y el análisis de su obra, Cesc Esteve examina los tratados teóricos sobre historiografía que circularon en la temprana Edad Moderna, Isabel Extravís Hernández ofrece una aproximación a figura de Jerónimo Zurita, Jesús Gascón Pérez coloca a este último cronista frente a su contemporáneo Jerónimo de Blancas y, por último, Alberto Montaner se sumerge en la obra de Miguel Martínez del Villar. La lectura de estas páginas lleva a replantearse cuestiones recurrentes en el estudio de la historiografía de la Baja Edad Media e inicios de la Moderna, como de qué modo comprender un concepto de autoría que incluye a actores materiales, ideólogos y promotores; qué tenían de pasado y qué de proyecto para el presente los relatos historiográficos; si eran aceptados, o hasta qué punto se contestaban, estos discursos diseñados para consolidar una realidad política, especialmente en un espacio tan caracterizado por la negociación como fue esta Corona; o quiénes leían estas obras - y cómo lo hacían - teniendo en cuenta que muchas de ellas se destinaban fundamentalmente a los contextos en los que habían sido creadas, ya fuesen cortes monárquicas y aristocráticas, ya ámbitos de producción documental urbana. Esto último invita a repensar la relación que pueden haber tenido la difusión y la propaganda en las sociedades preindustriales, y a preguntarse si los canales de comunicación política utilizados por entonces se limitaban a transmitir apenas la esencia de los mensajes, estando los escritos destinados solamente a las élites políticas e intelectuales.

El volumen abre también interrogantes que van mucho más allá del ámbito de los estudios sobre historiografía. Por ejemplo, plantea hasta qué punto condicionan nuestra aproximación a otras épocas las divisiones cronológicas que creamos o aceptamos, precisamente, para tratar de entender mejor el pasado; o, en la línea de lo que se señalaba unas frases atrás, de qué modo el control de lo simbólico jugó un papel en el desarrollo del Estado. La publicación, de hecho, se encuadra dentro de un proyecto de investigación centrado en sus agentes en la Baja Edad Media, entendiendo por tales aquellos que cooperaban con la administración, contribuyendo tanto a su expansión como a su robustecimiento burocrático. Concretamente, reúne la versión escrita de los trabajos presentados en un encuentro científico, celebrado en Zaragoza en octubre de 2018, que abordaba el modo en que la ideología de la Corona fue siendo construida a través de la historiografía. El enfoque subrayaba la relación de los historiadores -incluyendo cronistas, dietaristas y analistas - con las funciones propagandísticas, entendiendo por tales las destinadas tanto a configurar como a comunicar los elementos simbólicos del poder monárquico. En el periodo abordado ello se habría traducido, 
de acuerdo con estas premisas, en subrayar tanto la legitimidad de ese poder como el centralismo que representaba. En un espacio tan amplio, variado y cambiante como el aragonés bajomedieval y moderno, este enfoque puede dar lugar a centenas de estudios, por lo que esperamos que haya, de ahora en adelante, muchos otros volúmenes dedicados a la temática. 